\title{
Schwierige Situationen bei der transurethralen Katheterisierung
}

In schwierigen Situationen, u.a. bei Via falsa oder Strikturen, kann es erforderlich werden, einen transurethralen Harnröhrenkatheter über einen Führungsdraht zu legen. Ein geeigneter zentral offener Katheter ist jedoch nicht immer zur Hand. Soll die Harnröhre dennoch über einen transurethralen Katheter geschient werden, so bietet die hier beschriebene Technik eine einfache Möglichkeit, einen beliebigen Katheter zu einem zentral offenen Katheter umzufunktionieren. Eine Alternative wären handelsübliche Katheterbohrer, die aber nicht immer verfügbar sind.

Zunächst wird zystoskopisch oder urethroskopisch der Führungsdraht in die Blase vorgelegt. Dann wird der Katheter, bspw. auf dem Röntgentisch, vorbereitet ( $\odot$ Abb.1a-f): Der Operateur perforiert die Katheterspitze mit einer 14G-Venenkanüle (orange) über ein seitliches Katheterauge, sodass die Spitze der Viggo die Katheterspitze zentral perforiert (gegen die Flussrichtung des Katheters von innen nach außen). Nach Entfernen der Nadel wird das steife Ende des Führungsdrahts retrograd durch die Venenverweilkanüle geführt (in Flussrichtung des Katheters von außen nach innen). Nach Entfernung der Kanüle kann der Draht mit dem steifen Ende weiter retrograd durch das gesamte Katheterlumen geführt werden, wodurch der Katheter komplett auf den Führungsdraht aufgefädelt wird. Beim Vorschieben des Katheters nach reichlicher Gleitmittelapplikation kann dieser jetztüberdenFührungsdrahtals Leitschiene bis in die Harnblase gleiten.

Dr. Tamas Hidas \&' PD Dr. Burkard Ubrig, Bochum

Korrespondenz:

PD Dr. Burkard Ubrig

Klinik für Urologie

Augusta-Krankenanstalt Bochum

Bergstr. 26

44791 Bochum
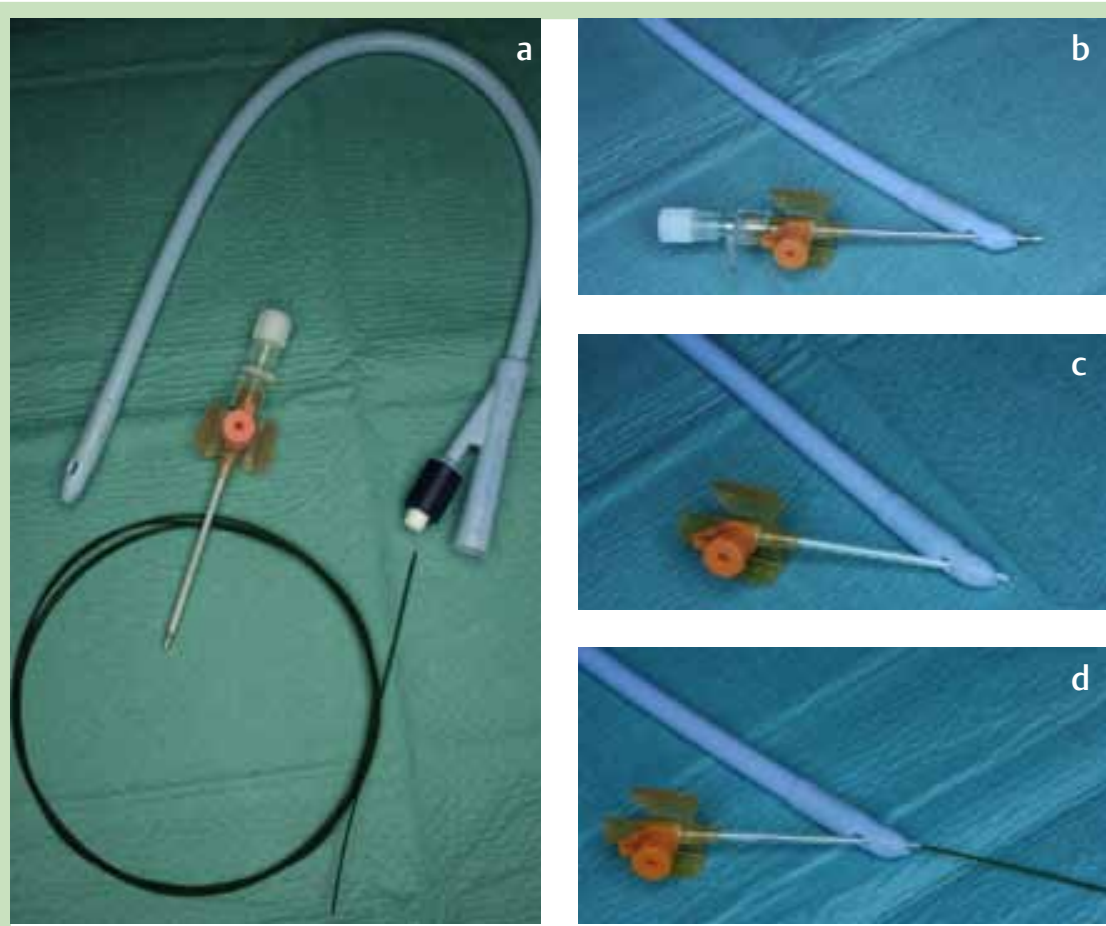

Tel. 02345172650

Fax 02345172653

E-Mail: b.ubrig@augusta-bochum.de

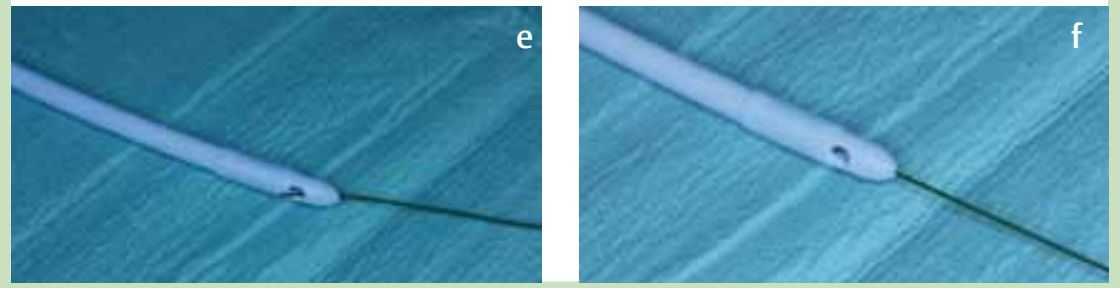

Abb. 1a-f Umwandlung eines beliebigen Katheters in einen zentral offenen Katheter. 